\title{
EMILIA PARDO BAZÁN EN LA ESPAÑA MODERNA (1889-1910)
}

\author{
MARISA SOTELO VÁZQUEZ \\ msotelo@ub.edu \\ Universitat de Barcelona
}

\begin{abstract}
Resumen
El objetivo de este trabajo es analizar las colaboraciones de Emilia Pardo Bazán en La España Moderna, la revista cultural más importante del último tercio del siglo XIX, comparable a la Revue des deux mondes. La escritora coruñesa contribuyó de forma decisiva junto a su director Lárazo Galdiano a la fundación de la revista para la que consiguió la colaboración de los mejores escritores de su tiempo. Ella misma ejerció la crítica literaria a través de artículos y reseñas, publicó algunos de sus trabajos más relevantes sobre feminismo, así como cuentos y novelas por entregas. El análisis demuestra que Pardo Bazán llevó a cabo una importante tarea cultural desde postulados eclécticos y con un marcado carácter regeneracionista y europeísta.
\end{abstract}

Palabras clave: Emilia Pardo Bazán, La España Moderna, crítica literaria, feminismo.

\begin{abstract}
The aim of this paper is to analyse Emilia Pardo Bazán's collaborations in La España Moderna, the most important cultural magazine of the last third of the 19th century and the Spanish equivalent to the Revue des deux mondes. The Galician writer -along with the magazine's editor, Lárzaro Galdiano- played a decisive role in the founding of the magazine for which she obtained collaborations from the best writers of her time. She contributed with articles and literature reviews and published some of her most relevant works on feminism, as well as short stories and novels in instalments. The analysis shows that Pardo Bazán performed an important role in Spanish culture, eclectically combining Regenerationism and Europeanism.
\end{abstract}

Keywords: Emilia Pardo Bazán, La España Moderna, Literary Review, feminism

Anales, 26, 2014, pp. 473-498

DOI: 10.14198/ALEUA.2014.26.20 


\section{Emilia Pardo Bazán y la génesis de La España Moderna}

Hacia el final de la década de los años ochenta del siglo XIX Emilia Pardo Bazán inicia la colaboración sistemática en diversas publicaciones periódicas sin abandonar nunca la escritura de novelas y cuentos. Es un período muy fecundo en la producción crítica de la autora de Los Pazos de Ulloa, que complementa su faceta ya consolidada de novelista. Para acercarnos a la situación de la crítica literaria en torno a estos años resulta de extraordinario interés el artículo de Urbano González Serrano «La crítica en España», publicado en La Ilustración Ibérica en 1890, testimonio del panorama cultural español visto a través de los ojos atentos de un eminente crítico, formado como tantos otros en las filas krausistas aunque pronto evolucionaría hacia el positivismo «frecuentando los análisis psicológicos y sociológicos» (Sotelo, 2002: 118).

González Serrano, partiendo de la distinción que establecía el naturalismo entre «arte productor y arte crítico»-que con posterioridad Henri Miterrand ${ }^{1}$ ha planteado en términos muy semejantes-, señalaba cómo difícilmente ambas facetas se daban de forma equilibrada en una única personalidad literaria salvo el caso excepcional de Goethe, a pesar de que la literatura moderna favorecía el nexo entre ambas dimensiones del arte literario en autores como los Goncourt, Daudet o el mismo Zola. Pero en estos casos, tal como observaba el crítico krausopositivista, dichos novelistas cuando ejercían como críticos caían fácilmente en el error de considerar que

su Preceptiva es la Preceptiva, y aquel amplio saber mirar y ver, primera condición de la crítica, queda reducido al saber mirar y ver lo suyo y en todas las producciones de los demás también lo suyo. Quieran o no, reducen el Cosmos y las manifestaciones de la vida y del arte a las personales y propias, que constituyen su carácter saliente (González Serrano 1890: 662).

En consecuencia, según González Serrano, casi inconscientemente los autores reducían el arte a la esfera de lo propio y muchas veces carecían del imprescindible tono de objetividad que debía garantizar la tarea crítica, porque, tal como había demostrado Taine ${ }^{2}$, no bastaba con profundizar en la obra examinada sino que el crítico debía penetrar

el santuario del medio interior del autor criticado, condición precisa para dilucidar los múltiples hilos que forman el tejido de la obra. El estudio

1. Henri Miterrand en Zola et le naturalisme propone la distinción del discurso teórico del naturalismo o modelo de producción y el análisis de las novelas o modelo de recepción. (Miterrand, 1986).

2. González Serrano consideraba a Taine como el crítico más importante del siglo y el que más había influido en el panorama cultural europeo, muy superior a Renán y a otros críticos coetáneos alemanes o ingleses. 
impersonal del medio interior en relación con el exterior, como la cópula de que resulta la fecunda creación del arte es la característica más valiosa del espíritu crítico (González Serrano 1890: 662).

Creo que, en buena medida, siguiendo una vez más a Taine, ese fue el objetivo de la crítica literaria de Emilia Pardo Bazán especialmente en la década de los años noventa con las colaboraciones en La España Moderna (1889-1910) y su revista unipersonal Nuevo Teatro Crítico (1891-1893). La autora, como es bien sabido, aunque no había practicado la crítica literaria de forma sistemática, tras los primeros años de aprendizaje en la prensa regional gallega ${ }^{3}$, se había dado a conocer a nivel nacional con los artículos sobre el naturalismo publicados en La Época (noviembre 1882-abril 1883), que gozaron de un extraordinario éxito de público a la vez que provocaban una acalorada polémica en los círculos literarios de la capital. Emilia Pardo Bazán, consciente del éxito de aquellos artículos de «escaramuza y de guerrilla» ${ }^{4}$, los recopila casi de forma inmediata en libro prologado por Clarín, con el sugerente título de La cuestión palpitante (1883). Unos años después contribuirá también decisivamente a la divulgación de la literatura rusa mediante las conferencias en el Ateneo de Madrid en 1886, recogidas en libro con el título de La revolución y la novela en Rusia, sin embargo, cuando González Serrano traza el panorama de la crítica en España injustamente no menciona su nombre entre la amplia nómina de críticos como Clarín, Menéndez Pelayo, Palacio Valdés, Revilla, Balart, Ortega Munilla, Orlando, Cavia o Yxart,

En España, muerto Larra, malogrado prematuramente Revilla, en silencio voluntario Balart, con movilidad versátil en pro de causas nobles Giner de los Ríos (F.), sutilizado y quintaesenciado Valera, recluido en su efectismo gongorino Ortega Munilla, derrochando su talento y su gracia Cavia en la nota del día, nostálgico y un tanto retraído Picón, Yxart circunscrito a sus valiosos comptes rendus y retirado Orlando (Lara), apenas si siguen dando en el yunque, aunque con la constancia relativa que indica el orden en que los nombramos Clarín, Menéndez Pelayo y Palacio Valdés. Los tres personifican

3. Me refiero a las colaboraciones en El Heraldo de Orense (1875-1880), dirigido por Valentín Lamas Carvajal, importante semanario del Rexurdimento que estoy en vías de publicar, y también a sus primeras colaboraciones en periódicos de Lugo y Pontevedra, además de la fundación y dirección de la Revista de Galicia (1880).

4. En carta a Menéndez Pelayo la autora le confiesa su sorpresa por el éxito de los artículos que tenían fundamentalmente un afán divulgativo y eran fruto de la síntesis de múltiples lecturas de literatura francesa: «Gracias por su bondadoso elogio de La Cuestión Palpitante, que es ciertamente un libro de guerrilla, de escaramuza, y de bien corta novedad en cuanto a las noticias que contiene. En Revistas, en tomos de la Biblioteca Charpentier, un peu partout, como dicen nuestrso vecinos, anda esparcida toda la erudición de esa obrilla; y figúrese usted qué fuentes tan recónditas» (Menéndez Pelayo, 1982: 217)

Anales, 26, 2014, pp. 473-498 
de momento, interín no tome plaza en esta ruda y difícil labor algún otro hombre de valía, la crítica moderna. Y puesto que el dogmatismo es una ciencia presumida y una audacia insostenible, y el escepticismo una falsa humildad, imponiéndose como señal de los tiempos el criticismo, sigámosle y hagamos crítica de los críticos (González Serrano 1890: 662).

En este contexto en que todo parece apuntar al despertar de la crítica de un letargo, en el que, si bien es cierto que nunca estuvo sumida del todo, comparativamente con otras naciones europeas singularmente Francia, evidenciaba una innegable pobreza y una ausencia de grandes maestros, si exceptuamos el caso de Larra, hay que situar la aparición de dos proyectos de revistas muy distintas entre sí pero con un rasgo en común, la presencia en ambas de doña Emilia, que va a desempeñar un papel fundamental en la gestación y fundación de La España Moderna, a la vez que entre 1891-1893 fundará y redactará totalmente en solitario su propia revista, el Nuevo Teatro Crítico.

El proyecto de La España Moderna, sin duda una de las revistas más prestigiosa del último tercio del siglo XIX, se fragua en Barcelona, a donde acude Emilia Pardo Bazán invitada por Narcís Oller con motivo de la Exposición Universal de 1888. La visita a Barcelona, la extraordinaria impresión que le causó la ciudad así como los fastos de la exposición serán evocados entusiásticamente por la autora coruñesa un año después en las crónicas de Al pie de la torre Eiffel con estas elocuentes palabras:

Esta ciudad es la más hermosa de España, y sin duda el día que consiga extenderse del Llobregat al Besós, podrá competir con las mejores de Europa y América. ¿En cuál otra ciudad de mi patria podría celebrase una Exposición Universal? seamos francos: calle Madrid; ríndase Bilbao; ninguna. Ella es la única donde el espíritu comercial y cierto cosmopolitismo hicieron posible esta solemnidad moderna (Pardo Bazán 1889: 71)

Estando en Barcelona traba amistad con un apuesto caballero más joven que ella, José Lázaro Galdiano ${ }^{5}$, financiero, mecenas y coleccionista de arte, que as-

5. Para algunos contemporáneos la relación fue algo más que amistosa, a juzgar por los comentarios de Narcís Oller y por los reproches que posteriormente le haría Galdós a doña Emilia, probablemente en base a la información recibida del novelista catalán (Oller, 1962:108-109). También en Cartas a Galdós, Pardo Bazán admite haber sido infiel, y suministra algunas pistas que dieron pie a que ya en su época se hablase del posible autobiografismo en la protagonista de Insolación, al relacionar el argumento de la novela con un viaje a Arenys de Mar que realizaron juntos la novelista coruñesa y Lázaro Galdiano, durante su estancia en Barcelona con motivo de la Exposición universal de 1888. Por su parte Galdós, dolido por la deslealtad de doña Emilia, plasma sus sentimientos en La incógnita y también en Realidad, a propósito de las cuales escribe la autora con gran expontaneidad: «Me he reconocido en aquella señora más amada por infiel y trapacera. ¡Válgame Dios, alma mía! puedo asegurarte que yo misma no me doy cuenta de como 
piraba a fundar una revista para la que espera contar, tal como se desprende de su epistolario ${ }^{6}$, con la ayuda de la autora coruñesa. La España Moderna (enero de 1889 a diciembre de 1910), de la que llegaron a publicarse unos trescientos números, con unas doscientas páginas aproximadamente, y que, en palabras de Raquel Asún, fue «única en su tiempo e iniciativa difícilmente superada en la historia cultural contemporánea» (Asún 1981-82: 133) seguía muy de cerca los modelos de otras publicaciones francesas afines y «nacía con el propósito de convertirse en una publicación que sea a nuestra patria, y en general a los países que hablen nuestra lengua, lo que a Francia la Revue des deux mondes: suma intelectual de la edad contemporánea» (Asún 1981-82: 133).

Es sobradamente conocido que si Lázaro Galdiano pudo llevar a cabo tan importante empresa cultural e editorial fue precisamente porque se supo rodear de los mejores escritores de su tiempo en las diversas disciplinas, historia, sociología, derecho, antropología y, sobre todo, arte y literatura. Nombres como Galdós, Clarín, Valera, Menéndez Pelayo, Altamira, Posada, Palacio Valdés, Balart, Sardà, Yxart y, sobre todo, Emilia Pardo Bazán hicieron posible que la revista se convirtiera en una inmejorable e imprescindible plataforma de intercambio y divulgación cultural en la España de finales del siglo XIX. Y a partir de 1900 las firmas de Baroja, Blasco Ibáñez o Unamuno prestigian aún más si cabe la publicación, además de las ya asiduas a lo largo de la vida de la revista, Gómez de Baquero, Andrenio, y Villegas, dos de los críticos con una presencia constante desde los primeros números.

De todos los escritores mencionados, sin duda, la colaboración de doña Emilia fue la más duradera, fructífera e importante de la primera época, llegando incluso su primera biógrafa, Carmen Bravo Villasante $e^{7}$, a sostener que dicha colaboración fue imprescindible en la trayectoria de la revista primero, y de la

he llegado a ésto. Se ha hecho ello solo; se ha arreglado como se arregla la realidad, por sí y ante sí, sin intervención de nuestra voluntad, o al menos, por mera obra del sentimiento, que todo lo añasca» (Pardo Bazán, 1978: 81). Palabras que confirman la tesis sostenida por la autora en Insolación al justificar la caida de la marquesa protagonista por la influencia y los efectos aniquilantes del extremado sol sobre su conducta.

6. Ha estudiado minuciosamente el epistolario y lo ha publicado la profesora Dolores Thion Soriano-Mollà, Pardo Bazán y Lázaro. Del lance de amor a la aventura espiritual (1888-1919). El epistolario cuenta con cuarenta y cuatro cartas en total, treinta y cuatro de ellas fueron dirigidas por la escritora a Lázaro Galdiano, y tal como señala la editora, la mayoría fueron escritas durante el período estival desde la Coruña, donde pasaba los veranos doña Emilia (Thion, 2003: 12-15).

7. Carmen Bravo Villasante sostiene que Pardo Bazán era quien realmente dirigía La España Moderna (aunque, suponemos que por error en la introducción a su edición, dice La Lectura), así escribe: «cuyo director era Lázaro Galdiano, aunque bajo cuerda, la verdadera directora era Emilia Pardo Bazán» (Bravo Villasante, 1972: 17) 
editorial homónima después. La profesora Raquel Asún, que había estudiado detenidamente el proyecto editorial de La España Moderna y la propia revista, sitúa la cuestión en sus justos términos cuando sostiene que «la función que doña Emilia desempeñó en la revista fue sugerir, informar, proteger y difundir esa empresa que tantas ilusiones despertara en ella, porque pensaba que venía a dignificar la profesión literaria y podía convertirse en vehículo de los mejores ingenios» (Asún 1981-82: 140-1), pues aunque la colaboración de Pardo Bazán fue activísima durante los primeros tres años tal como ha demostrado el estudio de la profesora Dolores Thion (2003: 54-99), donde, sin duda, iba a jugar un papel determinante, dado su buen conocimiento de la literatura europea francesa y rusa singularmente, será en la creación de la editorial que a partir de 1891 dependería de la revista, y desde la que se impulsó un número importante de traducciones de las que fue ella prácticamente la única responsable ${ }^{8}$. «Su amistad con los Goncourt, Bourget, Zola facilitaba la traducción de títulos de estos autores y, en general, de toda la escuela naturalista francesa, que ella conocía bien» (Asún 1981-82: 145). La editorial, que jugó un importante papel en la europeización de la cultura española en los albores del siglo Xx, fue tutelada en los primeros años por la autora coruñesa imponiendo sus gustos evidentemente francófilos, Zola, Goncourt, Barbey d'Aurevilly fueron traducidos entre otros autores. También ella misma prologó Humo de Turgueniev y La casa de los muertos de Dostoievski, que se vertían al español a través de una traducción francesa.

La España Moderna se publicó desde enero de 1889 a diciembre de 1910. La colaboración de Emilia Pardo Bazán, más allá de las tareas fundacionales de la publicación, abarca desde enero de 1889 , fecha en que aparece el primer trabajo, se trata del cuento Morrión y boina, a agosto de 1901, en que ve la luz la última entrega de un amplio estudio sobre «La mujer española». Entre estas dos fechas la autora publica en la revista de Lázaro ficción (cuentos y novelas por entregas); historia y crítica literaria, reseñas de libros; crónicas de la exposición universal de París (julio-octubre de 1889) y crónicas viatorias, así como artículos sobre cuestiones de actualidad relacionadas con la situación de la mujer y la cuestión académica?.

8. Aunque como se puede comprobar en la correspondencia entre Lázaro Galdiano y Clarín, éste último era también partidario de emprender la tarea de traducir a los novelistas europeos más importantes de la época y así se lo aconseja al editor, primero públicamente en un «Palique» del Madrid Cómico (23-II-1889), y posteriormente en una carta «recomendando a Lázaro que prescindiera de publicar los ampulosos discursos tan en boga en la época, que procurase fomentar la novela, incluso traduciendo las buenas que aparecían en el extranjero» (Rodríguez Moñino, 1951: 53).

9. En apéndice se detallan todas las publicaciones de Pardo Bazán indicando la fecha y el tomo de la revista en que fueron publicadas. 
Para analizar las colaboraciones literarias de doña Emilia en estos años es preciso tener en cuenta en paralelo aquellos trabajos que de forma más o menos circunstancial iba entregando a la prensa diaria y que muchas veces actuaban como reclamo publicitario de trabajos posteriores más amplios, que vieron la luz en la revista de Lázaro Galdiano o en el Nuevo Teatro Crítico que iba a fundar dos años después, en 1891. Y aunque en crítica no hay cuestiones infalibles, lo cierto es que todas las colaboraciones de esta época ponen de manifiesto su eclecticismo, la oportunidad de sus juicios, la claridad de sus ideas en terrenos como el naturalismo o la literatura rusa, que conocía tan bien, y, sobre todo, su enorme interés y curiosidad por las nuevas corrientes de pensamiento a la par que una extraordinaria y nada despreciable intuición literaria.

\section{España, su carácter y su cultura en las colaboraciones de Pardo Bazán en La España Moderna (1889-1890)}

Las colaboraciones de Emilia Pardo Bazán en la revista de Lázaro Galdiano a lo largo de 1889, primer año de publicación, aparte de las específicamente relacionadas con su tarea de cronista de las literaturas gallega y bable ${ }^{10}$, son una miscelánea sobre asuntos diversos, no todos de igual interés, pues desde los artículos sobre cuestiones feministas o, más específicamente entonces, sobre la cuestión académica, en los que la autora una y otra vez defendía incansablemente la igualdad de la mujer y el hombre en el terreno intelectual, a un buen número de reseñas bibliográficas también entre sí muy heterogéneas, en las que a veces de forma imprevista afloran ideas no solo acertadas desde la perspectiva literaria y estética, sino desde una perspectiva más amplia que podríamos llamar histórico-cultural. En estos trabajos doña Emilia plantea lo que con frase un tanto vaga pero muy significativa podríamos llamar una reflexión desde múltiples perspectivas de la esencia y el carácter de la cultura española, tal como ocurre en el final de la reseña del libro de Guillén de Robles $^{11}$, La leyenda de José, hijo de Jacob, y la de Alejandro Magno, sobre dos leyendas árabes documentadas entre los moriscos aragoneses de mediados

10. De la misma manera que Dña.Emilia era la encargada de reseñar la literatura gallega y bable, de la literatura vasca se encargó Arturo Campión; de la catalana, Joan Sardà; de la mallorquina, José M. Quadrado y de la valenciana Teodoro Llorente, gran amigo de la autora.

11. Guillén de Robles (Málaga, 1846-Granada, 1926). Abogado e historiador orientalista fue miembro de la Real Academia de la Historia. Su trabajo como arabista empieza a ser conocido con la publicación de Málaga musulmana (1880) y sobre todo con la publicación de Leyendas moriscas.

Anales, 26, 2014, pp. 473-498 
del siglo XVI, en donde con palabras que parecen preludiar el interés que por el legado árabe mostraría años más tarde Américo Castro, la autora escribe:

Cuando tanta falta nos hace la publicación de textos en los cuales estudiar nuestra historia civil y literaria, el libro del Sr. Guillén Robles viene a ofrecer a los escritores excelentes motivos de estudio y nuevos puntos de vista para futuras indagaciones que acaben de ilustrar uno de los asuntos más interesantes y conmovedores de nuestra historia; asunto muy estudiado, muy debatido, pero en el cual, según parece, no se ha pronunciado todavía la última palabra. Asunto que comprende la vida y la suerte de los restos de un pueblo antes dueño de España, victorioso y prepotente, antes culto y sabio; vencido después, humillado y envilecido, que contemplaba tristemente su pasado glorioso, mientras que por culpas propias y ajenas se condensaba sobre él la tempestad que había de arrancarle de la tierra que tanto amó y esparcirle a los cuatro vientos, como éstos esparcieron en muchas aldeas de España las cenizas de sus abandonados hogares (Pardo Bazán, 1889a:186).

Acendrado patriotismo que se evidencia no sólo en la defensa del estudio del legado cultural árabe como factor integrante y conformador de nuestra historia e identidad nacional, sino también en las reseñas de libros de autores hispanoamericanos, tal es el caso del chileno Jorge Huneeus con sus Estudios sobre España ${ }^{12}$, cuando Pardo Bazán defiende el acercamiento cultural de España a aquellos países para librarlos del excesivo influjo francés ${ }^{13}$, pues entendía que la producción literaria de los países hispanoamericanos venía a ser «nuestro renuevo, el vivero de nuestra raza» (Pardo Bazán, 1889c: 202).

12. Obra sobre la que también Don Juan Valera escribirá apelando igualmente a conceptos de raza y de lengua con ánimo de afianzar los lazos con los escritos hispanoamericanos: «En resolución: yo no he de negar que usted y yo discrepamos en bastantes puntos. No se opone esto, sin embargo, a que yo aplauda el interesante trabajo de usted, a que me admire de lo mucho que usted ha estudiado y leído, a que celebre como es justo la facilidad, pureza y elegancia de su estilo; a que convenga perfectamente con usted en ese empeño en que todos los hombres de lengua o raza española nos confederemos intelectualmente y para ello nos conozcamos mejor» (Valera, 1947: 350).

Con anterioridad, desde Bruselas, el 22-VI-1886, Valera había ya escrito una carta al autor chileno proporcionándole datos sobre el panorama literario español. También recogido en en Obras Completas III (Valera, 1947: 344-346).

13. Así, a propósito del libro de Jorge Huneeus, escribe: «Entre las muchas ligerezas que solemos cometer los españoles, figura en primer término la de no otorgar suma importancia a la producción literaria de nuestras antiguas colonias. La tiene desde el punto de vista patriótico y social, aunque esencialmente ofrezca cierto carácter rudimentario, y haya sido hasta el día, con honrosas excepciones, pálido reflejo de la extranjera o arcaica reminiscencia de la nuestra en los siglos XVI y XVII. Mas nosotros estamos obligados a estudiar la aurora que hoy luce, y debemos regocijarnos al comprobar que cada día se acercan más a la madre común los países hispanoamericanos, y, sacudiendo el yugo de la imitación francesa, buscan sus modelos, no sólo en los antiguos clásicos españoles, sino en los grandes escritores contemporáneos» (Pardo Bazán, 1889c: 201-202). 
Algo parecido se observa en las cuatro cartas sobre la Exposición, resumen de las publicadas en La Época a lo largo de 1889, y recogidas posteriormente por la autora en el volumen de obras completas titulado Al pie de la Torre Eiffel. Colección de veinticinco crónicas misceláneas relacionadas con la Exposición Universal celebrada en 1889 en París, y en las que de manera indirecta y sutil se observa como al comentar los adelantos técnicos o industriales de otros países europeos, Pardo Bazán lamenta la pobre representación de las delegaciones españolas, a excepción en aspectos muy concretos, como la orfebrería, de los expositores catalanes, entre los que destacaba la obra del modernista Masriera.

Y aunque tanto las cuatro cartas ${ }^{14}$ publicadas en La España Moderna como las restantes, todas ellas recogidas en Al pie de la torre Eiffel, son crónicasreportajes, unas veces entre líneas y otras de forma más explícita se manifiestan impresiones que patentizan, más allá de la curiosidad de la autora por la Exposición, el verdadero móvil regeneracionista que guiaba sus reflexiones en esta época:

España ha aparecido en el Certamen como un pueblo que tiene color local, riquezas agrícolas naturales, aptitudes varias y fecundas, y sin embargo se encuentra afligido por la decadencia lastimosa que todos vemos, que todos reconocemos al menos verbalmente, y sobre cuyas causas y remedios se opina de tan diversos modos. Propiamente yo creo que lo de España no se puede llamar decadencia, sino desorganización o desbarajuste general, con aleación de atonía y pereza (Pardo Bazán, Carta XXV, [1889]: 304-5).

Atonía, pereza y abulia que Pardo Bazán observa en la conducta de los españoles en 1889 y que preludia el diagnóstico de los males de la patria que harán casi unánimemente los regeneracionistas y noventayochistas unos años después. Hay, por tanto, en las palabras de la autora, en el tono acentuadamente pesimista, algo a veces difícil de precisar y demostrar, que preludia algunas de las ideas más fecundas del Unamuno pre-noventayochista en su ideario del En torno al casticismo ${ }^{15}$, tal es el caso de las palabras finales de la carta XX,

14. Dedicadas, en palabras de la propia autora, a «En la primera hablaré del aspecto general de la Exposición, su recinto y edificaciones, manera de entrar en ella y de pasar allí el día gratamente; en la segunda diré algo de lo que menos me divierte, pero que, sin embargo, constituye la parte esencial y útil de las Exposiciones, la industria, en las instalaciones de los diversos países; en la tercera trataré de los espectáculos y de la moda, y en la cuarta pasaré revista al elemento exótico, que encuentro sumamente original y entretenido» («Cartas sobre la Exposición» La España Moderna, T.VII, VIII, IX y X; (31-VII, 31-VIII, 31-IX y 31-X-1889) pp.167-181, 139-153, 119-131 y 85-105, respectivamente (Pardo Bazán, 1889d).

15. Por cierto tan influenciado también por Taine, a quien Unamuno con toda seguridad había leído atentamente, y había tenido muy en cuenta al formular su teoría de la

Anales, 26, 2014, pp. 473-498 
titulada «Bavaria», cuando, tras haber hablado del respeto de otras naciones por sus hombres de genio, por aquellos que habían contribuido a ennoblecer su patria, escribe, bajo influencia tainiana, valorando también el esfuerzo del hombre anónimo que era, en cierta medida, el verdadero protagonista de la historia, o de la «intrahistoria» unamuniana: «Al pie de aquel templete, el viejo soldado me pareció personificación de la gloria anónima la que no se escribe en lápidas de bronce, y es sin embargo tan necesaria a la grandeza de las naciones como la invisible sangre a las venas y al organismo» (Pardo Bazán, carta XX, [1889]: 258).

Porque a Dña. Emilia no se le ocultaba que esta abulia tan característica del carácter español mezclado además con un cierto quijotismo hacía que nuestro país no fuese tenido en cuenta en el concierto de las naciones europeas, y de ahí se desprende necesariamente un profundo pesimismo y, a la vez, la denuncia de la ignorancia de lo auténticamente español por parte de los europeos, especialmente los vecinos franceses. En consecuencia la autora lamenta que se siga siempre hablando de España en base a clichés de su ancestral intransigencia ideológica ${ }^{16}$ cuando no de brutalidad o de primitivismo, esgrimiendo en último término los consabidos argumentos sobre la crueldad de la Inquisición española o de las corridas de toros. Sobre este último aspecto, Pardo Bazán critica que, incluso periódicos tan bien informados como Le Figaro, tengan una ignorancia supina de todo lo español acompañada a menudo de una presunción exclusivista, típicamente francesa, que hace que todo aquello que no sea a la manera gala sea considerado puro salvajismo. En estos términos se expresa doña Emilia sobre la proverbial hidalguía y el quijotismo de los españoles:

Pero nosotros, mansos corderos del turismo. Nosotros, que entramos en Francia resueltos a dejar que nos esquilen a trueque de probar nuestra hidalguía y finura (todo español acepta toda cuenta, es tradición y proverbio), nosotros somos el Quijote reidero, el figurón internacional, la víctima propiciatoria (Pardo Bazán, carta XIV, [1889]: 186).

El fragmento evidencia el profundo españolismo de la autora por encima incluso de su consabido entusiasmo por todo lo francés que, sin embargo, no le impide denunciar sin paliativos: «tienen los franceses un género de presunción

intrahistoria en los cinco ensayos de En torno al casticismo (1895), que se publicaron inicialmente en la revista de Lázaro Galdiano.

16. Vuelve a evocar la famosa anécdota sobre la Inquisición española, que había contado en los «Apuntes Autobiográficos», al rememorar entonces cómo conoció a Víctor Hugo (Pardo Bazán, 1974:720). 
exclusivista, que sería muy cómica si no fuese muy molesta y depresiva para el resto de la humanidad» (Pardo Bazán carta XIV, [1889]: 185)

Y por último, con un gran sentido profético que le iba a acarrear más de un disgusto y polémica ${ }^{17}$, Pardo Bazán censuraba al ejército español por sus enormes e injustificados gastos y su pésima organización que estaba llevando a la patria a la ruina ${ }^{18}$. Desgraciadamente diez años después, con el desastre del 98 y la pérdida de las últimas colonias, las palabras premonitorias de la autora cobrarán pleno significado, y a ello se referirá explícitamente y con acentuado pesimismo en el prólogo ${ }^{19}$ al volumen de sus obras completas en el que recogió las mencionadas crónicas de la Exposición:

A ser menos española, caería en la tentación de alegrarme viendo, no confirmados, sino sobrepujados hasta un límite que espanta, mis juicios de diez años hace, y aplicado por los sucesos cruel correctivo a la tempestad de brutales injurias que estos juicios desencadenaron contra mí; pero de estos triunfos de egoísmo no acierto yo a extraer sino hondas tristezas, así como de las injurias sólo extraje inconmensurable desprecio. Se me acercan ahora muchas personas y me dicen la frase de más melancólico sonido: «Razón tenía V.! ¡Cómo profetizó V. entonces!» Y ven con sorpresa los que me interpelan así, que yo incapaz de rectificar una tilde cuando la agresión me recrudece el sentimiento de independencia inherente a la dignidad profesional del escritor, en las actuales circunstancias, lejos de engreirme con el apoyo de la opinión que está llegando a extremos de censura jamás presentidos, hasta imposibles de presentir en 1889, aparezco inclinada a no juzgar al Ejército de mar y tierra con más rigor que a otras instituciones, clases y organismos de nuestra enferma y decaída patria (Pardo Bazán [1889]: 6-7).

Palabras que evidencian un hondo patriotismo del que brota la denuncia de los males y la decadencia de la patria, y que prepara de forma progresiva la

17. Según una carta de doña. Emilia dirigida al director de La Época y publicada el 21-XI1889, varios oficiales de la guarnición de la Coruña se habían incomodado por algunas frases de la escritora con respecto al ejército y, sobre todo, por considerar que se excedía al juzgar temas tan alejados de su competencia. De dicha polémica se hicieron eco por estas fechas El Liberal y El Globo (18-XI-1889). De ahí que la autora utilizara las páginas de La Época para puntualizar el verdadero alcance de sus palabras.

18. Como es sabido estas opiniones Pardo Bazán disgustaron profundamente a algunos mandos del ejército, produciendose un intercambio de cartas en la prensa diaria, entre las que sobresale el artículo titulado «Al pie de la Torre de los Lujanes», que apareció en un periódico de la Coruña, firmado con unas iniciales y fue interpretado como una contestación a las palabras vertidas por la autora.

19. En dicho prólogo, de 1899, afirma que el motivo que la impulsa a recoger las crónicas periodísticas sobre la Exposición en un libro era que «a toda hora, en toda conversación, en periódicos y libros, en el Congreso, en el Senado, y no hay que decir si en el extranjero, está puesto a discusión y sometido a implacable crítica lo que han dado en llamar prestigios del ejército español» (Pardo Bazán, [1889]: 5).

Anales, 26, 2014, pp. 473-498 
reflexión sobre España que hará doña Emilia desde múltiples perspectivas en los años inmediatos al desastre del 98. Múltiples perspectivas que van desde algunos de los relatos que integran el volumen Cuentos de la patria $a^{20}$, o a través de ensayos, artículos y conferencias como la que pronunciará en París, al filo del fin de siglo con el título La España de ayer y de hoy, la muerte de una leyenda $a^{21}$, reflexión sobre el desastre finisecular, que perfilará aun más si cabe su ideario regeneracionista.

\section{Los escritos sobre feminismo en La España Moderna}

La cuestión feminista encontró en las páginas de La España Moderna una importante plataforma de difusión. Los escritos feministas se concentran entre 1889-1890, que son años importantes en la reflexión sobre la situación política, social y cultural de la mujer en la vida española. Además, por esas mismas fechas Emilia Pardo Bazán publica dos novelas muy significativas, Insolación y Morriña, que desencadenarán la ruptura definitiva con Leopoldo Alas, Clarín. Precisamente Insolación puede considerarse uno de las novelas más decididamente feministas de la autora coruñesa. Sin embargo, la preocupación de doña Emilia por las cuestiones relacionadas con la formación y el papel de la mujer en la sociedad de su tiempo venía de lejos, se había referido a ella a través de la ficción narrativa en los primeros años de praxis naturalista en novelas como La Tribuna, La dama joven o Los pazos de Ulloa, y de forma explícita en los «Apuntes autobiográficos», con que, a petición de Yxart, prologó precisamente esta última novela. Vuelve a la cuestión femenina en 1889, cuando tras presentar su candidatura a la Academia y ser rechazada, publica «La cuestión Académica», que pocos meses después reproduce en El Liberal (1-3 mayo, 1889). Artículo en el que dirigía dos cartas ficticias a Gertrudis Gómez de Avellaneda en las que glosaba la cuestión de la presencia de

20. Entre los cuentos que componen el volumen titulado Cuentos de la patria merece especial atención El caballo blanco, basado en la leyenda del caballo del apóstol Santiago. El mencionado cuento encierra una lección a todas luces claramente regeneracionista, pues se trata de quitarle las galas al corcel de Santiago ya que no tiene que participar en gloriosas batallas sino dedicarse a una tarea mucho más humilde y prosaica pero también más pragmática y fructífera, la de arar la tierra de la empobrecida España. Para un estudio más minucioso de este y otros cuentos de la autora ver (Paredes Núñez, 1979)

21. La España de ayer y de hoy, conferencia en la que Dña. Emilia pretendía destruir la leyenda heroica que mantenía al país anclado en el recuerdo de viejas y trasnochadas glorias pasadas para sentar las bases de una nueva España que era necesario construir entre todos, objetivo que descubre su peculiar visión de España como patria común por encima de los localismos y regionalismos a la par que patentiza el perfil noventayochista de la autora. Véase Marisa Sotelo, 1999: 355-368. 
las mujeres en la Academia. También un año después reproduce en la revista de Lázaro Galdiano el estudio sobre La mujer española que había publicado en la revista londinense Fortnightly Review en 1889 y que había suscitado un extraordinario interés a nivel internacional, tal como se deduce del artículo de Gabriela Cunninghame aparecido también en las páginas de La España Moderna 1890 (Thion, 2003: 83).

En el primero de estos trabajos doña Emilia crítica la discriminación de que era objeto el talento femenino en los ambientes españoles ilustrados. Las cartas iban dedicadas a Gómez de Avellaneda porque su candidatura había sido rechazada en 1853 y Pardo Bazán quería demostrar que desde entonces las cosas no habían cambiado nada en la Real Academia. Sin embargo, el inmovilismo discriminatorio de la Academia no la acobarda, más bien al contrario, convencida de sus méritos, se declara «candidata perpetua, archiplatónica y eterna» (Pardo Bazán, 1889f: 176). Y tras sostener que el respeto y la equidad se habían perdido ya durante el siglo XVIII, obligando a Feijoo a escribir la Defensa de las mujeres, insiste en denunciar hasta qué punto la discriminación se seguía manteniendo a lo largo de todo el siglo XIX. Y con manifiesta ironía imagina como se recibiría la petición de una mujer excepcional como Santa Teresa si resucitara y se propusiera entrar en la Real Academia ${ }^{22}$ :

De modo, Gertrudis, que si hoy por permisión divina resucitase nuestra santa patrona Teresa de Jesús, y con la contera del báculo abacial que he venerado en Ávila llamase a las puertas de la Academia Española, supongo que algún vozarrón estentóreo le contestaría desde dentro: «Señora Cepeda, su pretensión de usted es inaudita. Usted podrá llegar a ser el dechado del habla castellana, porque eso no lo repartimos nosotros: bueno; usted subirá a los altares, porque allí no se distingue de sexos; corriente; usted tendrá una butaca de oro en el cielo, merced a cierto lamentable espíritu demagógico y emancipador que aflige a la Iglesia: concedido; ¿pero sillón aquí? Vade retro, señora Cepeda. Mal podríamos, estando usted delante, recrearnos con ciertos chascarrillos un poco picantes y muy salados que a última hora nos cuenta un académico [...] En las tertulias de hombres solos no hay nada más fastidioso que una señora, y usted, doña Teresa, nos importunaría asaz (Pardo Bazán, 1889f: 182).

Afirmaciones como la transcrita le valieron la respuesta de Valera «Las mujeres y la Academia». El segundo trabajo sobre feminismo, publicado con el

22. Sobre este aspecto la profesora Dolores Thion suministra una serie de datos muy interesantes que evidencian el carácter combativo de la escritora, pues en 1891 en la Editorial de La España Moderna «entre los anuncios de nuevos libros aparecía un curioso folleto titulado ¿Académicas? (Soliloquio), que si bien es anónimo es muy probable que naciese al volar de la pluma de la propia doña Emilia. En él se traslucen tanto el ingenio, la vivacidad y la amenidad del estilo de la escritora» (Thion, 2003: 86).

Anales, 26, 2014, pp. 473-498 
título de La mujer española, se divide en cuatro partes claramente diferenciadas. Una primera de carácter general y en las tres restantes el análisis se ciñe a las características de la vida de la mujer española en las diferentes clases sociales, la aristocracia, la clase media y el pueblo. En la primera, dedicada a una revisión histórica de la situación de la mujer española en los siglos XVIIIXIX, la autora advierte como la mujer en realidad se había amoldado en todo a los criterios masculinos, y en consecuencia no se la podía responsabilizar totalmente de su penosa situación:

Para el español -insisto en ello- todo puede y debe transformarse, solo la mujer ha de mantenerse inmutable y fija como la estrella polar. Preguntad al hombre más liberal de España qué condiciones tiene que reunir la mujer según su corazón, y os trazará un diseño muy poco diferente del que delineó Fray Luis de León en La perfecta casada, o Juan Luis Vives en La institución de la mujer cristiana, si no es que remontando más la costumbre de los tiempos, sube hasta la Biblia y no se conforma sino con la mujer fuerte (Pardo Bazán, 1890b: 103)

La segunda parte dedicada a revisar la situación de la mujer en la aristocracia, clase que ella conocía bien, advierte cómo los vicios, el lujo, la molicie, que se señalan siempre en esta clase social se asocian exclusivamente a la mujer, juzgando que a ello había contribuido indirectamente la literatura, pues tanto Pereda en La Montálvez como el padre Coloma en Pequeñeces, el primero por desconocimiento de la clase social retratada, y el segundo por excesiva rigidez moral, las mujeres salían muy mal libradas. En este aspecto Emilia Pardo Bazán adelanta algunos de los juicios sobre la polémica de Pequeñeces que verán la luz en el Nuevo Teatro Crítico (abril de 1891).

En cuanto a la clase media, la preferida por los novelistas de este período pero también la más difícil de acotar, señala la dificultad de la mujer burguesa para labrarse un porvenir mediante el trabajo, pues «contadas son las profesiones que la mujer está autorizada para desempeñar en España; pero más contadas aún las mujeres de la clase media que se resuelven a ejercerlas» (Pardo Bazán, 1890: 122). Emilia Pardo Bazán, como también Clarín, sostenía que, aunque resultase aparentemente contradictorio, gozaba de mayor independencia la mujer del pueblo que la burguesa, precisamente porque la mujer del pueblo sabía que tenía forzosamente que ganarse la vida con su trabajo, tal como ella había ya demostrado con su novela La Tribuna (1884), en la que describía el trabajo de las obreras de la fábrica de Tabacos de Marineda, mientras que la burguesa aspiraba a vivir a la sombra del padre primero y del marido después. En coherencia con la trayectoria de su cigarrera marinedina sostiene aquí: 
Hoy por hoy, existe entre la mujer de la clase media y la del pueblo español este abismo profundo; la del pueblo tiene la noción de que debe ganar su vida; la burguesa cree que ha de sostenerla exclusivamente el trabajo del hombre. De aquí se origina en la burguesa mayor dependencia, menos originalidad y espontaneidad. La mujer del pueblo será una personalidad ordinaria, pero es mucho más persona que la burguesa» (Pardo Bazán, 1890b: 123).

También pone el dedo en la llaga del mal más frecuente de la clase media, tantas veces denunciado por Galdós. La clase media en su empeño de imitar a la aristocracia desembocaba muy a menudo en el consabido «quiero y no puedo», aunque el problema fundamental, a juicio de la autora coruñesa, radicaba en las carencias educativas que sufría la mujer de su tiempo:

El sistema educativo donde predominan las medias tintas, y donde se evita como un sacrilegio el ahondar y el consolidar, da el resultado inevitable, limita a la mujer, la estrecha y reduce, haciéndola más pequeña aún que el tamaño natural, y manteniéndola en perpetua infancia. Tiene un carácter puramente externo: es, cuando más, una educación de cascarilla; y si puede infundir pretensiones y conatos de conocimientos, no alcanza a estimular debidamente la actividad cerebral» (Pardo Bazán, 1890b: 125)

Finalmente, la cuarta entrega, dedicada a la mujer del pueblo es indudablemente la parte más interesante. Desde los postulados claramente tainianos de la raza, el medio y el momento histórico, doña Emilia analiza las características de la mujer del pueblo en las diferentes regiones españolas, pues el determinismo del medio ambiente y los rasgos distintivos del carácter son, a su juicio, decisivos en la configuración de estas mujeres, tanto las del medio urbano como las campesinas. En consecuencia escribe: «mejor que ninguna clase, conserva el pueblo en España carácter nacional [...] los tipos étnicos más puros, así en lo físico como en lo moral, en el pueblo se conservan, y, sobre todo, en la mujer del pueblo» (Pardo Bazán, 1890b: 127). Con agudeza señala las características distintivas de la mujer catalana que ha «adquirido las condiciones propias de una raza laboriosa y adelantadísima», para subrayar la constancia en el trabajo y el espíritu pragmático que la diferencia de la obrera o chula madrileña, que tiene unas características propias:

En cambio, la hembra de los barrios bajos de Madrid -mucho más interesante para el artista- es un rezago del pasado, una supervivencia de la España clásica; es la figura que se pinta en los abanicos y en las panderetas; es el modelo que seduce y atrae al pintor de costumbres, como Mesonero Romanos o Pérez Galdós. Descendiente de las antiguas majas y manolas, la chula conserva la desvergüenza en el hablar, la prontitud arrebatada y colérica del genio, la intensidad afectiva y la vehemencia de sus desatadas pasiones. La chula no ha variado desde que don Ramón de la Cruz escribió el Muñuelo (Pardo Bazán, 1990b: 143). 
Completa el análisis de las características de la mujer del pueblo con unas breves pinceladas referidas a la mujer andaluza, que presenta muchas semejanzas con la chula madrileña, ambas mujeres de «corazón y sangre». Entre las obreras andaluzas sobresale el prototipo de la cigarrera, mujer de fuertes convicciones republicanas con un acusado sentido de la justicia, tal como se evidencia en las fábricas de tabacos de Madrid y Sevilla.

En cuanto a los tipos femeninos del norte subraya las diferencias de la mujer vasca frente a la gallega y asturiana. Con mucho detalle analiza Emilia Pardo Bazán los rasgos definidores de la psicología de la mujer vasca, que considera «helada en el terreno pasional» pero muy «ardorosa en el político», sobre todo cuando supone vulneradas sus tradicionales creencias. Esta mujer, que habita una de las partes, junto a Cataluña, más industriosas y desarrolladas de España, aparece ante la mirada de doña Emilia con estas características distintivas:

No se parece en nada a la española tal como se la figuran los extranjeros, apasionada, semi-árabe. Al contrario: la mujer de Vizcaya, Guipúzcoa y Álava es una figura de líneas severas, hasta podría decir ásperas y rudas, y una de las hembras más morales de Europa. [...] el tipo étnico y la complexión psíquica de la raza eúskara ni aún se parece a la de la restante población del litoral cantábrico, a pesar de las similitudes topográficas y climatológicas. Mientras que la mujer de Asturias y Galicia presenta contornos redondeados, fresca encarnación y facciones de gracioso diseño, la mujer vasca es algo dura y angulosa de líneas, y en su frente y en sus pómulos se lee una tenacidad inquebrantable (Pardo Bazán, 1990b: 145).

Finalmente cierra este análisis estableciendo entre las mujeres del pueblo tres o cuatro grupos distintivos. El grupo catalán vascongado con «cierta analogía, por más que distinga a las eúskeras su fogosidad político-religiosa» (Pardo Bazán, 1890b: 146). El grupo andaluz y madrileño que «revela afinidades estrechísimas» y descubre «la preponderancia del elemento semítico o africano» ((Pardo Bazán, 1890b: 146), y el territorio propiamente céltico, o sea Asturias y Galicia, tan semejantes por su clima y su naturaleza a las provincias vascas, produce, «a causa de la diferencia de raza, una mujer que forma con la eúskara perfecto contraste» (Pardo Bazán, 1890b: 146). Sobre la mujer galaicoasturiana, que la autora coruñesa había observado atentamente y pintado con detalle en sus novelas, escribe:

La mujer galaico-asturiana es de tierno corazón; la política no le quita el sueño, ni le importa nada que se modifique el código fundamental, ni que nos manden don Carlos o Alfonso XIII. Apasionada de sus hijos, no los inmolaría en aras de ninguna idea social: y en cuanto a insensibilidad amorosa, baste decir, como único dato, que es raro que una aldeana vaya al altar sin haber dado al mundo prole. Conviene advertir que, realizando el programa de Juan 
Jacobo Rousseau, las aldeanas de este grupo son libres en sus costumbres mientras no llega la hora de casarse, pero después guardan fidelidad a sus maridos (Pardo Bazán, 1890b: 147).

El artículo termina señalando irónicamente la contradicción entre la falta de igualdad entre los sexos en muchas de las esferas de la vida social, que, sin embargo, no rige en las labores más duras, como en la mísera realidad del trabajo de los labradores y jornaleros, sin que ello haya levantado la más mínima protesta entre los seguidores de las ideas de Prudhomme:

En mi país, Galicia, se ve a la mujer, encinta o criando, cavar la tierra, segar el maíz y el trigo, pisar el tojo, cortar la hierba para los bueyes. Tan duras labores no levantan protesta alguna entre los profundos teóricos de la escuela de Monsieur Prudhomme, que, a penas se indica el menor conato de ensanchar las atribuciones de la mujer en otras esferas, exclaman llenos de consternación y santo celo «que la mujer no debe salir del hogar, pues su única misión es cumplir los deberes de madre y esposa». El pobre hogar de la mísera aldeana escaso de pan y fuego, abierto a la intemperie y al agua y al frío, casi siempre está solo. A su dueña la emancipó una emancipadora eterna, sorda e inclemente: la necesidad (Pardo Bazán, 1890b: 148).

\section{La crítica literaria: Reseñas bibliográficas en La España Moderna}

De las reseñas propiamente literarias publicadas en La España Moderna merece especial atención la dedicada a Mezclilla de Clarín. Varios son los motivos por los que nos detenemos en este artículo; en primer lugar, por ser el único dedicado a las obras de Clarín por parte de Emilia Pardo Bazán, máxime teniendo en cuenta que por estas fechas las relaciones de cordialidad entre ambos autores se habían enfriado bastante, y se había iniciado un distanciamiento progresivo que culminaría en la negativa del crítico asturiano a reseñar las dos últimas novelas de la autora, Insolación y Morriña ${ }^{23}$ en La España Moderna. Ruptura que tuvo, además, como telón de fondo una serie de rumores y comentarios sobre la amistad entre doña Emilia y Lázaro Galdiano, que contribuyeron a acentuar el perfil frívolo de la autora. Por todo ello Clarín se negó a someterse a los criterios del editor y dejó abruptamente de escribir en dicha revista, sin embargo, poco después publicaba en uno de sus Folletos literarios, Museum, una reseña de la Poética de Campoamor y dos artículos durísimos dedicados a las mencionadas novelas de la autora, que juzga con manifiesta arbitrariedad, sobre todo Insolación.

23. Sobre este aspecto proporciona abundantes datos el trabajo de Rodríguez Moñino, 1951: 47-70.

Anales, 26, 2014, pp. 473-498 
En este contexto, interesa situar el artículo de Emilia Pardo para juzgar con mayor objetividad las opiniones de la autora sobre un volumen misceláneo que recogía trabajos publicados por el autor de La Regenta en años anteriores. Sergio Beser resumió muy bien las ideas y propósitos que Clarín exponía en el prólogo-Advertencia del mencionado volumen crítico, señalando que «el radicalismo aparece más atenuado que en libros anteriores y respeto al naturalismo, aunque continúa defendiéndolo, son numerosos los ataques a los escritores mediocres que siguen este movimiento; así el artículo «A todos y a ninguno» (Beser 1968: 94). También, al referirse a la acogida que el libro tuvo entre los críticos de la época, el profesor Beser resume las ideas expuestas por doña Emilia en su reseña de la España Moderna, pero, a nuestro juicio, hay un aspecto de la mencionada reseña no suficientemente valorado, que se ha revelado fundamental en las interpretaciones posteriores de la obras de Clarín, me refiero a la novedad que suponía la última de las ideas dominantes que a juicio de Pardo Bazán se desprendía de Mezclilla, aunque fuesen artículos de muy variado asunto. Ideas que la autora enumeraba así:

primera, un pesimismo intelectual absoluto, o dígase firme convencimiento de que los tiempos son tristes, la vida literaria languidece, y en España apenas piensa nadie en el arte. Segunda, atenuación de este pesimismo al analizar los libros de media docena de autores: acaso no suban de este número, acaso no lleguen a él, hechas ciertas salvedades, porque una cosa es que Clarín tenga a Zorrilla, v. gr., por gloria nacional, y otra que juzgue actual y del tiempo nuevo semejante gloria. Tercera, implacable resolución de no admitir para su misantropía pesimista sino grandes y eficaces consuelos, y fustigar o desdeñar la literatura secundaria, sobre todo cuando viene precedida de hiperbólicos elogios y acompañada de pretensiones intolerables. (...) Cuarta y última, una idea muy singular, muy sutil, que el escritor deja entrever apenas, y que a mí no me sorprende poco ni mucho ver delineada en un alma tan dolorida y en una complexión neuro-biliosa como la de Clarín; una idea ¿lo diré? religiosa y cristiana (Pardo Bazán, 1889b: 189-190)

Algunos años más tarde, Pérez de Ayala al esbozar un retrato intelectual del que fuera su maestro escribía, ahondando prácticamente en el mismo sentido, que Clarín había sido un «espíritu profundamente religioso» (Pérez de Ayala 1961: 20), palabras del discípulo que confirman la opinión de Pardo Bazán, que fue la primera en percibir en los trabajos de Clarín una idea religiosa, cristiana, sin que ello supusiese apriorismos ni prejuicios estéticos en su valoración global, sino más bien al contrario, justificando las posibles causas de aquella peculiar religiosidad clariniana con estas elocuentes palabras en las que de forma indirecta se hace a la vez tan presente el verdadero y último sentido de La Regenta: 
Los que recuerden aquella profunda distinción que establece D. Joaquín Rubió y Ors, en su Historia de la sátira, entre el elemento satírico pagano y el cristiano, podrán aplicarla a Clarín, quien posee en alto grado esa risa de la tristeza que prefería el docto catedrático de la Universidad de Barcelona. Por otra parte, el curso de los años; la residencia en una provincia, donde se vive moralmente solitario y se despierta la necesidad de la contemplación; la sugestiva sombra de una catedral (aquella catedral de Vestusta que el mismo Clarín describió); la lectura de obras de esas que elevan el espíritu y lo conducen a detenerse en los problemas filosóficos, a la vuelta de los cuales están los religiosos; todo explica ciertas auras que corren por las páginas de Mezclilla, y al pronto parecen inadecuadas a la índole del libro (Pardo Bazán, 1889b: 189)

Porque en realidad, qué es sino profunda «soledad moral» lo que acosa al espíritu sensible y lleno de dudas religiosas de Ana Ozores en medio de un ambiente provinciano pacato, monótono e hipócrita? Por tanto, creo que doña Emilia que no había dicho nada en la prensa cuando se publicó La Regenta, (1884-85), hecho que probablemente disgustó a Clarín, si tenía en cambio muy presente aquella novela, como máximo exponente del espíritu del autor al redactar las citadas líneas sobre los ensayos de Mezclilla. Estaba, en consecuencia, doña Emilia descubriendo el perfil más auténtico y verdadero de aquel Clarín de fin de siglo idealista e espiritualista, que estudios, como los del profesor Yvan Lissorgues (1983) ${ }^{24}$ primero y Gonzalo Sobejano (1985) ${ }^{25}$ después, han terminado de dibujar.

Por último, otro aspecto de la reseña que revela el buen olfato crítico de la escritora coruñesa es la mención explícita de algunos artículos del volumen considerados hoy por los clarinistas como indudablemente los mejores, y entre los que sobresale el dedicado a «Baudelaire» $\mathrm{y}$ «A todos y a ninguno», donde advierte cómo Clarín ponía freno a los nuevos naturalistas, vulgares

24. Véase La pensée philosophique et religieuse de Leopoldo Alas (Clarín), 1875-1901. Paris, CNRS, 1983. Lissorgues defiende la tesis de un Clarín genuinamente «idealista» y «espiritualista», aspecto que ha subrayado abundamentemente en la biografía Clarín en sus palabras, Oviedo, Nobel, 2007.

25. Quien en Clarín en su obra ejemplar afirma que Alas desdeñó del positivismo todo menos su contribución al análisis científico, pero siempre sin perder su apetencia metafísica ni su inquietud religiosa, y escribe: «Tal apetencia, tal inquietud habitaron siempre la conciencia de Clarín, lo mismo en la mocedad que en la edad madura, pero hubieron de intensificarse a partir de 1890, no por un "cambio de luz" repentino, ni por obediencia a una moda europea (aborreció la moda con asco semejante al de Flaubert), sino por culminación de un proceso que arrancaba de sus propias raíces y que halló fomento en experiencias y circunstancias más íntimas que generales. En el prólogo a sus Cuentos morales, en 1896, confesaría como idea capital de sus invenciones la idea del Bien unida a la que infunde vida y calor: Dios» (Sobejano, 1985: 31-32)

Anales, 26, 2014, pp. 473-498 
imitadores de Zola y Goncourt, en plena sintonía con las ideas de la propia autora por estas mismas fechas.

Entre 1890 a 1891 el resto de reseñas bibliográficas, todas ellas muy breves, que aparecen firmadas por doña Emilia en la revista de Lázaro Galdiano aportan algunos juicios sobre la situación y la naturaleza de la crítica al afirmar en «Ultimas modas literarias», sobre All'avanguardia de Vittorio Pica que:

La crítica ha de reaccionar contra esta acción disolvente del tiempo; ha de diferenciarse del público en no ser olvidadiza, y asemejarse a la Divinidad, para la cual no hay pasado ni futuro, sino presente sólo. No debe increparse a los críticos si elogian o veneran, ante todo, las obras maestras que el público va arrumbando, y si de tiempo en tiempo se las recuerdan, como se recuerda al desmemoriado nieto de cien héroes las glorias de sus difuntos abuelos. La crítica ha de embalsamar a los autores, ya que el público los pulveriza y entierra; y desde este punto de vista, casi me entran impulsos de asegurar que la crítica, propiamente dicha, no se ejerce sino sobre obras que ya están a la vez sancionadas, glorificadas y dadas al olvido por el público, refrescando a éste la memoria de que no pierda enteramente sus venerandas huellas (Pardo Bazán, 1890a: 162).

La función del crítico como depositario de la memoria cultural colectiva y la apelación al clasicismo no se ajustaba a la actitud de Pica, crítico napolitano, que adoptaba una actitud de «precursor» y adaptador a su patria de las nuevas modas literarias europeas ${ }^{26}$, puesto que según la autora Italia no había tenido una verdadera generación de novelistas como Francia, Rusia o España, y por tanto se veía obligada a adaptarse a los modelos extranjeros. Además, Emilia Pardo señala que el interés fundamental de la obra de Pica reside en el estudio de los simbolistas y decadentistas franceses, singularmente Verlaine y Mallarmée, cuando escribe:

opino que el joven crítico acierta cuando dice que Verlaine y Mallarmé han cometido el delito de ser innovadores en materia estética, y el ridículo es de antiguo arma esgrimida con feroz complacencia y no sin cierta eficacia, al menos por algún tiempo, contra todo innovador (Pardo Bazán, 1890a: 169).

Las preferencias estéticas de Pardo Bazán sobre estos dos poetas se concentran en Verlaine, de quien emparentándolo con San Juan de la Cruz, escribe:

siempre preferiré a Verlaine, por su libro singularísimo Sagesse, digno de figurar en el mismo estante que las Fioretti di San Francesco, que la Imitación, que los versos de San Juan de la Cruz, que todos esos libros admirables,

26. Por ello escribe: «El papel de Pica se reduce, pues, a señalar a su patria las últimas modas extranjeras, y alentar a los escritores, si no genio revolucionario e iniciador, al menos talento para aprovechar e interpretar, en su esfera, las ideas estéticas más o menos nuevas, pero al fin recientes, de otros países». (Pardo Bazán, 1890a: 163). 
amargos como el absintio y dulces como miel de romero, que nos enseñan a comprender la nada de las cosas, y, levantando nuestro ánimo, nos hacen volver los ojos hacia la patria eterna (Pardo Bazán, 1890a: 170)

Y tras colocar al maestro del simbolismo francés en línea con los mejores poetas ascéticos y místicos, matiza aun más sus preferencias:

Verlaine siente más que Mallarmé, y aunque católico únicamente por accesos, con intervalos de terrible desorden moral, cuando acierta a pulsar la cuerda de dolor sublime y poesía que resuena en los tremendos dogmas católicos, su fondo es incomparablemente superior al de Mallarmée, en quien resalta una especie de melancolía pagana y suave, propiamente musical (Pardo Bazán, 1890a: 170-1).

Afirma que Mallarmée estaba influenciando profundamente a los poetas noveles europeos, mientras que su influencia sobre la cultura española era menor porque ésta aun no había llegado al grado de enervamiento de la sensibilidad y al decadentismo que caracterizaba lo que en Francia todo el mundo llamaba ya «la melancolía de fin de siglo».

En las dos últimas reseñas de 1890, una dedicada a las poesías del Duque de Rivas, prologadas por Cañete ${ }^{27}$, con un tono «avinagrado y pesimista», y otra, dedicada a dos libros sobre Las mocedades del Cid de Merimée y Le geste del Cid de Restori. Ambas reseñas, aunque la autora se confiesa entusiasta admiradora del personaje histórico, no tienen excesivo interés, pues en ellas no esboza siquiera ningún juicio de valor estético, se trata simplemente de reclamos publicitarios que parafrasean el contenido de los libros. Prácticamente ocurre lo mismo en un artículo titulado «El fuerismo en la novela», publicado en El Imparcial, (27-I-1890), y que años después recogería junto con otros trabajos en el volumen de Polémicas y Estudios literarios, y en el que únicamente indica de forma un tanto rápida y superficial algunos elementos de la ideología «fuerista vasco-navarra» a través de la personalidad de Arturo Campión ${ }^{28}$, afirmando que dicha ideología estaba algo pasada de moda, muy

27. Manuel Cañete (Sevilla, 1822 - Madrid, 1891). Crítico literario y teatral, radicalmente antinaturalista, muy conocido en los ambientes políticos y periodísticos de Madrid. Colaboró además de en la prensa diaria en El arte en España y en La Ilustración Española y Americana. Clarín y Fray Candil criticaron frecuentemente el excesivo academicismo de sus apreciaciones y juicios literarios, mientras que Valera decía de él «Cañete, uno de nuestros mejores críticos» (Valera, 1947: 344).

28. Arturo Campión, crítico encargado de reseñar las producciones de la literatura vasconavarra en La España Moderna, fue también colaborador de la revista Euskalerría. Jurista notable, poeta y filólogo, conocido sobre todo como propagador de ideas religiosas y regionalistas, así como autor de Consideraciones a cerca de la Cuestión foral y los carlistas en Navarra, (Madrid,1874) y de la Gramática de los cuatro dialectos literarios de la lengua euskera (Tolosa,1886). Prologó con un texto titulado «La Regeneración y

Anales, 26, 2014, pp. 473-498 
en la línea de otras opiniones sobre el regionalismo de la autora por estos mismos años. También de estas mismas fechas data un artículo de Emilia Pardo Bazán publicado en La Época (12-XII-1889) sobre Richepin, a quien compara con Francisco Villón, pues como él «eleva el argot canallesco a la dignidad poética» (Pardo Bazán, 1889b). Ya que el autor de Las Blasfemias era a su juicio un mongol salvaje sin Dios, patria, ni ley que cultivaba un apasionado nihilismo. En consecuencia el artículo interesa más por lo que apunta sobre la compleja personalidad del autor que sobre su obra poética.

Entre 1891 y 1897-8, en que aparecen los últimos trabajos críticos de la autora en La España Moderna, sus colaboraciones se van distanciando, de manera que además del artículo dedicado a la última novela del ciclo de Les Rougon-Macquart de Zola, Le Docteur Pascal (Pardo Bazán septiembre-1893), y otro anterior, dedicado a los Goncourt (Pardo Bazán marzo-1891), que está en relación directa con la traducción y prólogo de Los hermanos Zenganno, que hizo la autora para la editorial de la mencionada revista, lo demás tiene un valor literario muy relativo, probablemente porque por aquellas fechas la autora ocupaba ya todo su tiempo en la preparación y eminente aparición de lo que sería su revista, El Nuevo Teatro Crítico. También entre 1899 y 1907 Emilia Pardo Bazán publica por entregas un importante trabajo sobre «La literatura francesa moderna», que se convertiría en la materia de sus volúmenes sobre dicha literatura dedicados a El Romanticismo, El Naturalismo y La Transición.

De la revisión y análisis de los trabajos de Emilia Pardo Bazán en La España Moderna se deduce su importancia decisiva de la autora en la fundación y consolidación del proyecto cultural de la revista de Lázaro Galdiano, a la par que sus colaboraciones evidencian un marcado afán regeneracionista y europeísta, siempre bajo el marchamo de la crítica ecléctica, que hunde sus raíces en el historicismo y el comparatismo.

\section{Bibliografía}

AsúN, Raquel (1981-2): «La Editorial de la España Moderna» ARCHIVUM, XXXIXXXII, Oviedo, 1981-2, págs.140-141.

BESER, Sergio (1968): Leopoldo Alas, crítico literario. Madrid, Gredos.

Bravo Villasante, Carmen (ed.) (1972): Emilia Pardo Bazán, La vida contemporánea. Madrid, Novelas y Cuentos.

- (ed.) (1978): Emilia Pardo Bazán, Cartas a Galdós, Madrid, Turner.

la verdad» la conferencia regeneracionista de Emilia Pardo Bazán en París, sobre «La España de ayer y la de hoy: la muerte de una leyenda», Madrid, Administración, 1899. 
Freire, Ana María (2005): «Emilia Pardo Bazán: Periodismo y Literatura en la prensa», en (J.M. González Herrán, C. Patiño, E. Penas, eds.), Emilia Pardo Bazán: estado de la cuestión» Coruña, Casa-Museo Emilia Pardo Bazán / Fundación Caixa Galicia, pp. 19-32.

GÓMEZ FERRER, Guadalupe (ed.) (1999): Emilia Pardo Bazán, La mujer española y otros escritos, Madrid, Cátedra, Col. «Feminismos 56», pp. 73-116.

GONZÁLEZ SERRANO, Urbano (1890): «La crítica en España», La Ilustración Ibérica, págs.662-663.

LisSORGUES, Yvan (1983): La pensée philosophique et religieuse de Leopoldo Alas (Clarín), 1875-1901. Paris, CNRS.

MiterRAND, Henri (1986): Zola et le naturalisme, Paris, PUF.

MenÉndez Pelayo (1982): Epistolario (ed. M. Revuelta Sañudo), T. IV (enero, 1883-noviembre, 1884), Madrid, Fundación Universitaria Española.

Oller Narcís (1962): Memòries literàries. Historia del meus llibres, Barcelona, Aedos.

PARDo BAZÁn, Emilia [1889]: «Recuerdo de Barcelona. Carta III». Al pie de la torre Eiffel. Obras Completas. T. XIX. Madrid, Renacimiento.

- (1889a): La leyenda de José, hijo de Jacob, y la de Alejandro Magno por F. Guillén Robles, La España Moderna, t. I (enero 1889), pp.

- (1889b): Mezclilla, por Clarín La España Moderna, t. II, febrero de 1889), pp. 189-190.

- (1889c): «Estudios sobre España, por Jorge Huneeus Gana», La España Moderna, T.VI, (junio-1889), pp.201-202.

- (1889d): «Cartas sobre la Exposición» La España Moderna, tomos VII, VIII, IX y X; (31-VII, 31-VIII, 31-IX y 31-X-1889) pp. 167-181, 139-153, 119-131 y $85-105$.

- (1889e): «La poesía actual francesa: Richepin»La Época, (12-XII-1889).

- (1889f): «La cuestión académica», La España Moderna, t.II, febrero de 1889, pp.173-184

- (1890a): «Ultimas modas literarias». (Sobre All'avanguardia de Vittorio Pica). La España Moderna, t. XIV (febrero-1890), pp.

- (1890b): «La mujer española», La España Moderna (tomos 17, 18, 19 y 20, mayo-agosto de 1890), pp. 101-113; 5-15; 121-131 y 143-154.

- (1973): «Apuntes Autobiográficos» Obras Completas, T.III. Madrid, Aguilar.

Paredes NúÑEZ, Juan (1979): Los cuentos de Emilia Pardo Bazán. Granada, Publicaciones de la Universidad de Granada.

Penas Varela, Ermitas (2003): Clarín, crítico de Emilia Pardo Bazán, Santiago de Compostela, Universidad de Santiago de Compostela, «Laia Maior», n. ${ }^{\circ} 17$.

PÉREZ DE AYALA, Ramón (1961): Amistades y recuerdos, Barcelona, Aedos.

RodríGuez MoÑino, Antonio (1951): «Clarín y Lázaro: un pleito entre escritor y editor (1889-1896)», Bibliofilia, V, Valencia, Castalia; pp. 49-70. Reeditado 
con el título de "Clarín» y Lázaro. Noticia de unas relaciones literarias (18891996), Madrid Fundación Lázaro Galdiano, Ollero y Ramos, 2001.

Sobejano, Gonzalo, (1985): Clarín en su obra ejemplar. Madrid, Castalia.

Sotelo VÁzQUez, Adolfo (2001): «Urbano González Serrano y el naturalismo» en el Naturalismo en España: crítica y novela, Salamanca, Almar, pp. 113-134. Sotelo VÁzQUez, M. ${ }^{a}$ Luisa (1988): Las ideas literarias y estéticas de Emilia Pardo Bazán (187-1921), Barcelona, Universidad de Barcelona. Microfichas.

- (1999): «Emilia Pardo Bazán ante la crisis del 98: La España de ayer y la de hoy: La muerte de una leyenda», La Crisis española de fin de siglo y la Generación del 98, Actas del Simposio Internacional (A. Vilanova y A. Sotelo, eds.), Barcelona, Universitat de Barcelona, 1999, pp. 355-368.

- (2002): «Fundamentos estéticos de la crítica literaria de Emilia Pardo Bazán», La elaboración del canon en la literatura española del siglo XIX. Actas del II coloquio de la Sociedad de Literatura Española del siglo XIX, Barcelona, PPU, pp.415-426.

- (2002): «Clarín y Emilia Pardo Bazán», en A. Vilanova y A. Sotelo (eds.) Leopoldo Alas «Clarín». Actas del Simposio Internacional (Barcelona, abril-2001), Barcelona, PPU, pp.161-185

- (2005): «Emilia Pardo Bazán: crítica e historia literaria», en (J.M. González Herrán, C. Patiño, E. Penas, eds.), Emilia Pardo Bazán: estado de la cuestión» Coruña, Casa-Museo Emilia Pardo Bazán /Fundación Caixa Galicia, 2005, pp. 131-180.

Thion SORIANo-Mollà, Dolores (2003): Pardo Bazán y Lázaro. Del lance de amor a la aventura cultural (1888-1919), Madrid, Fundación Lázaro Galdiano/ Ollero y Ramos.

VAlerA, Juan (1947) «Carta a D. J. Hunneus Gana» (Bruselas, 22-VI-1886), en Obras Completas. T.III, Madrid, Aguilar, pp. 344-349. 


\section{Apéndice}

Colaboraciones de Emilia Pardo Bazán en La España Moderna

A) Obras de Ficción

\section{Cuentos}

Morrión y boina (T.1, enero de 1889).

Un destripador de antaño (T.13, enero de 1890)

Travesura pontificia (T.15, marzo de 1890)

Planta montés (T.24, diciembre de 1890)

Las tapias del camposanto (T. 25, enero de 1891)

\section{Novelas por entregas}

Una cristiana (T.20, agosto de 1890).

La prueba (T.21, septiembre 1890), Reproducen capítulos de las dos novelas que forman un mismo proyecto narrativo.

Adán y Eva (Ts. 61-62-63-64 y 65, enero-mayo de 1894)

Los tres arcos de Cirilo (Ts. 73 y 74, enero-febrero de 1895)

Adán y Eva (Ciclo). Memorias de un solterón (Ts. 85, 86, 87 y 89, enero, febrero, marzo y mayo de 1896).

El saludo de las brujas (Ts. 97-98-99-100-101 y 102, enero a junio de 1897).

El niño de Guzmán (Ts. 121, 122 y 123, enero-marzo de 1899).

Un drama (Ts. 77-78 y 79, mayo-julio de 1895).

B) Historia y crítica literaria

«Últimas modas literarias» (T. 14, febrero de 1890)

«Dos cidianistas extranjeros» (T. 23, noviembre de 1890)

«Edmundo de Goncourt y su hermano» (T. 27, marzo de 1891)

«Teoría del consuelo» (T. 37, enero de 1892)

«Los poetas épicos cristianos (Dante, Tasso, Miltón)»(Ts. 71 y 72, noviembrediciembre de 1894).

«Escritores franceses contemporáneos: Eduardo Rod» (Ts. 108-109, diciembreenero 1897-1898).

«La literatura moderna en Francia»(Ts.132, 133, 134, 135, 136, diciembre 1899-abril 1900. Ts. 140, 141 y 144 agosto-septiembre y diciembre de 1900; Ts. 145,146 , enero-febrero de 1901; Ts. 155 , 156, noviembre-diciembre de 1901; Ts. 157 y 168, enero y diciembre de 1902; T. 217, 218, 219 y 228 eneromarzo y diciembre de 1907; Ts. 229 y 240 enero y diciembre de 1908; T. 241, enero de 1909. 
Reseñas

La leyenda de José, hijo de Jacob, y la de Alejandro Magno por F. Guillén Robles (T.1. enero de 1889).

Mezclilla, por Clarín (T. 2, febrero de 1889)

De la poesía gallega por el Marqués de Figueroa (T. 2, febrero de1889)

La Eloísa portuguesa de Sor Mariana Alcofurado (T. 6, junio de 1889)

Estudios sobre España por Jorge Huneeus Gana (T. 6, junio de 1889)

Poesías de El Duque de Rivas (T. 15, marzo de 1890)

El Doctor Pascual por E. Zola (T.57, septiembre, 1893).

C) Crónicas de la Exposición Universal de París (1889) y crónicas viatorias

Cartas sobre la Exposición (Ts. 7, 8, 9, 10, julio-octubre de 1889)

El viaje por España (T. 83, noviembre de 1895).

D) Artículos sobre cuestiones femeninas

La cuestión académica (T. 2, febrero de 1889)

La mujer española (Ts. 17, 18, 19 y 20, mayo-agosto de 1890)

Fecha de recepción: 02/04/2014

Fecha de aceptación: 01/07/2014 